\title{
Enhanced energy dissipation in stepped chutes
}

\section{S. James, A. G. Main and J. Moon}

\section{H. Chanson, The University of Queensland, Brisbane, Australia} The writers must be congratulated for their innovative paper. Their contribution is a timely reminder that most research on stepped chute hydraulics has been narrowly limited to flat identical horizontal steps in straight prismatic rectangular channels. ${ }^{1}$ For completeness, the discusser wishes to provide relevant information on early stepped spillways and related works. He also adds some pertinent comment.

Enhancement of energy dissipation may be provided by superposition of small and large steps. In Australia, the Malmsbury (1870) and Upper Coliban (1903) stepped spillways were designed with a combination of large drops $(h=2-4 \mathrm{~m})$ and stepped chutes ( $h=0.305 \mathrm{~m}$ ) (see Fig. 1 and Reference 1, pp. 48 and 73). At design flows, the drops operate with a nappe flow and the chutes in skimming flow regime. Their successful operation for more than a century suggests that the design is sound. On the model of the Kennedy's Vale dam $(h / l=1)$, Stephenson superimposed occasional large steps to smaller steps and he observed a 10\% increase in energy dissipation for this model.
While the writers showed the effects of step lateral deflections on the rate of energy dissipation, they did not elaborate on three-dimensional flow patterns or construction practice. Step deflections are expected to induce shock waves and sidewall standing waves that affect the sidewall design and chute operation. Three-dimensional effects will be further amplified in non-straight channels. In a flat stepped chute $(h / l=0 \cdot 06)$, Chanson and Toombes ${ }^{3}$ measured sidewall wave heights in excess of the critical depth. ${ }^{4}$ They also observed splashing heights exceeding three to five times the critical depth, and they documented one prototype experience. Practically, a lateral deflection of steps lacks geometrical simplicity; for example, it is not suitable for roller-compacted concrete construction. Altogether these issues may offset the advantages of the design.

Overall, the authors must be congratulated for their innovative results. Their contribution highlights the need for further comprehensive studies of stepped chute hydraulics with nonflat horizontal steps.
Two early French stepped spillways were equipped with V-shaped steps. Completed in 1834, the Tillot dam spillway was equipped with two series of small V-shaped steps (oriented forward) (see Appendix 1). Note the channel convergence and the absence of downstream stilling basin (Fig. 2). The Pas du Riot dam was completed in 1873 and it is equipped with a masonry stepped chute. The steps are sloped upwards and V-shaped, oriented backwards (Fig. 3). The spillway capacity was increased during the 1990 dam refurbishment, without modification of the original stepped chute. Both steeped spillways are still in use, highlighting the soundness of design.

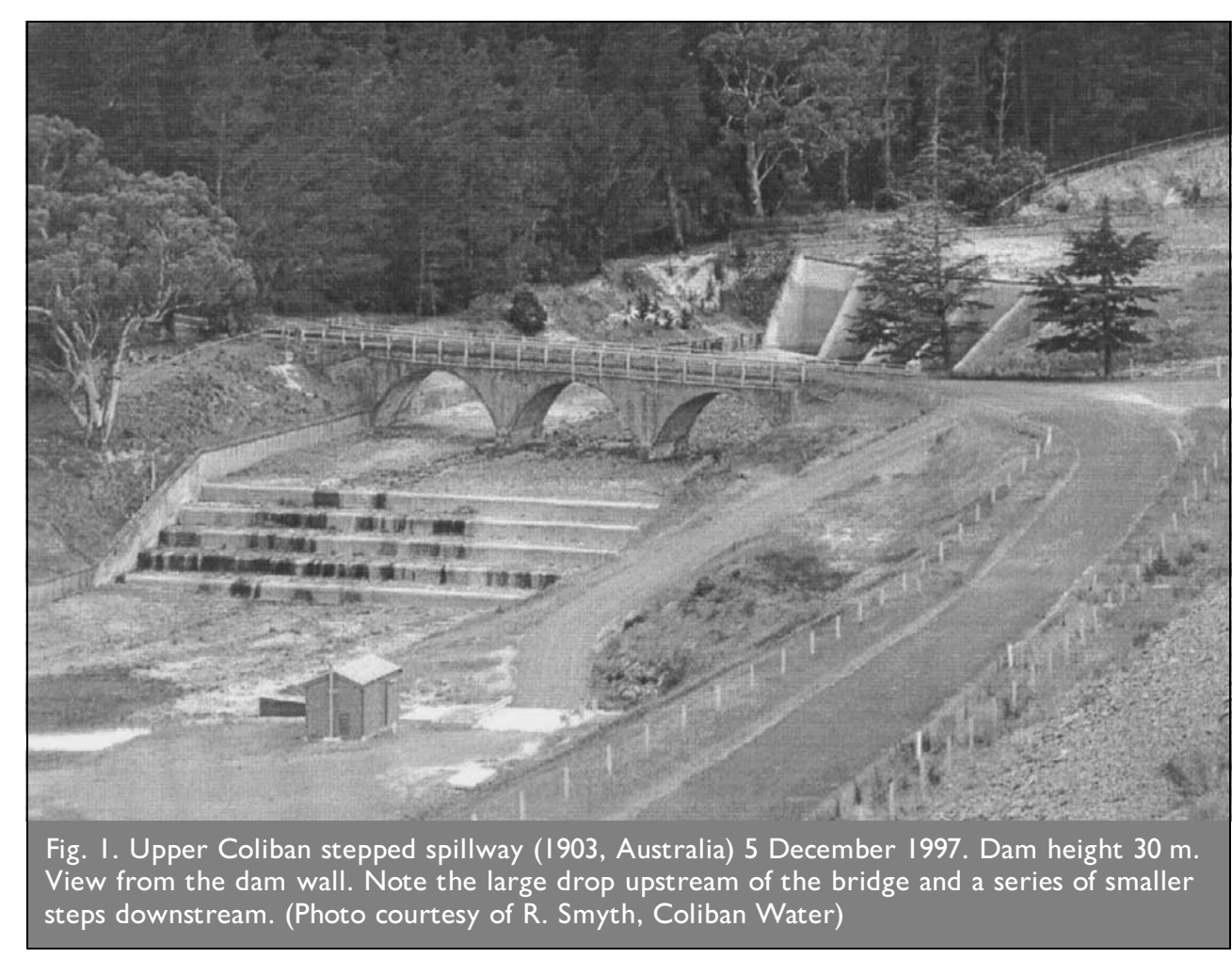




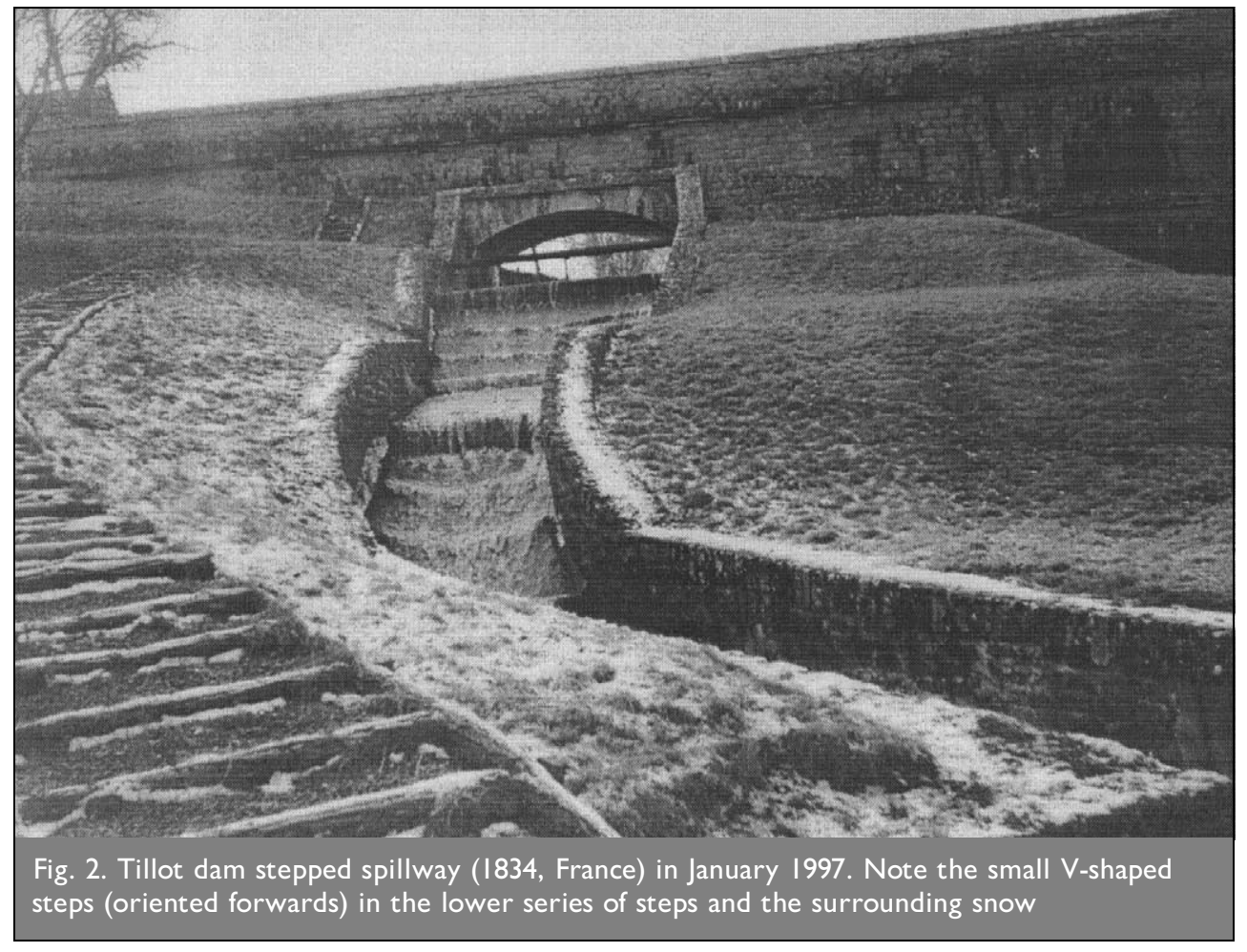

and construction developments.

We acknowledge that the hydraulic performance of a structure involves various flow characteristics, but our study focused only on the energy dissipation effects of the different step configurations. While water surface profiles were not measured, the V-shaped step edges did not produce obvious changes in maximum water levels along the side walls, but this needs further investigation. The scale of the experiments was too small for assessment of possible influences on aeration and splashing. Three-dimensional flow patterns in non-straight channels are indeed likely to be modified by lateral deflections such as induced by our configurations, but the effects need not necessarily be undesirable-judicious location and alignment of step edges (or orientations of surfaces) may in fact ameliorate some problems associated with channel curvature.

As intimated by Dr Chanson, hydraulic performance is not the only issue in successful design, and must be balanced with economic, structural and construction considerations. We have only proposed a hydraulically effective option that may improve a design in some situations, such as for relatively

\begin{tabular}{|llll|}
\hline Drop No. & W:m & $h: m$ & $1: m$ \\
\hline 1 & 5.5 & 0.68 & $1 \cdot 18$ \\
2 & 5.2 & 0.62 & 1.24 \\
3 & 4.8 & 0.41 & 0.83 \\
4 & 4.5 & 1.18 & 8.6 \\
5 & 2.35 & 0.91 & $1 \cdot 11$ \\
6 & 2.2 & 0.56 & 1.24 \\
7 & 2.2 & 0.64 & 1.44 \\
8 & 2.3 & 1.08 & N/A \\
\hline
\end{tabular}

Note: $W=$ channel width

Table I. Step dimensions of the Tillot dam spillway

\section{APPENDIX I. HISTORY OF THE TILLOT DAM}

Built between 1830 and 1834, the Tillot dam was designed for the water supply of the Canal de Bourgogne (France). The structure is a straight rubble masonry gravity dam with four downstream buttresses (dam height $\sim 9.2 \mathrm{~m}$ ). In 1838, the dam wall had to be reinforced. The catchment area is $5.5 \mathrm{~km}^{2}$, the reservoir capacity is $0.52 \times 10^{6} \mathrm{~m}^{3}$ and the annual rainfall is about $850 \mathrm{~mm}^{5}$ The spillway, located on the right bank, is a rubble masonry construction (Fig. 2). It consists of a long flat crest followed by two series is no downstream energy dissipator. The design flow rate

Author's reply

Chanson's comments and his valuable contribution to stepped spillway and chute design. The use of steps for theme on which many variations are possible and structures are a salutary reminder of the value of a design - there are potential rewards in revisiting early design features in the light of more recent analysis 
narrow structures where roller-compacted concrete construction is not feasible.

\section{REFERENCES}

1. Chanson H. The Hydraulics of Stepped Chutes and Spillways. Balkema, Lisse, the Netherlands, 2001, 384 pp.

2. StePHENSON D. Stepped-energy dissipators. Proceedings of an International Symposium on Hydraulics for High Dams, IAHR, Beijing, China, 1988, pp. 12-28-12-35.

3. Chanson H. and Toombes L. Flow Aeration at Stepped
Cascades. Department of Civil Engineering, University of Queensland, Australia, June 1997, Research Report No. CE155.

4. Toombes L. Experimental Study of Air-Water Flow Properties on Low-gradient Stepped Cascades. PhD thesis, Department of Civil Engineering, University of Queensland, Brisbane, Australia.

5. ORTH F. Die Verlandung von Staubecken. (The siltation of reservoirs.) Bautechnik, 1934, 12, No. 26, 345-358 (in German). 